\title{
On the Impermissibility of Telling Misleading Truths in Kantian Ethics
}

\author{
Cameron Shelley \\ Centre for Society, Technology and Values, University of Waterloo, Waterloo, Canada \\ Email: cam_shelley@yahoo.ca \\ Received February 24 ${ }^{\text {th }}$ 2012; revised March $18^{\text {th }}, 2012$; accepted April $6^{\text {th }}, 2012$
}

\begin{abstract}
Sandel (2009) has recently revisited the issue of the moral permissibility of telling misleading truths in a Kantian ethical framework. His defense of its permissibility relies on assimilating it to simple truth telling, and discounting its relationship with simple lying. This article presents a refutation of Sandel's case. It is argued that comparison of misleading truths with telling truths or lies is inconclusive. Instead, comparison with telling of leading truths is appropriate. With this comparison in view, it is clear that telling misleading truths is not consistent with the Categorical Imperative, meaning that they are not morally permissible from a Kantian perspective.
\end{abstract}

Keywords: Kantian Ethics; Misleading Truths; Truth; Lying

\section{Did Not Have Sexual Relations with That Woman}

Sandel (2009) has recently re-presented the issue of the moral permissibility of telling misleading truths in the framework of Kantian ethics. The purpose of this article is to examine Sandel's defense of misleading truths and present an argument as to why this defense does not succeed.

Sandel takes up the canonical example of President Clinton assuring Americans that, "I did not have sexual relations with that woman, Ms. Lewinsky”. It might reasonably be concluded from this assurance that the President believed that he and Ms Lewinsky did not have any sort of sexual encounter. In the event, the President took his assurance to mean only that he and Ms. Lewinsky did not engage in any mutual sexual activity; she pleasured him but not vice versa. In short, the President said something that he believed to be the case but that he anticipated would be misinterpreted by his audience, to his advantage.

Sandel defends this sort of procedure as moral, from a Kantian perspective, because it "pays homage to the truth" (p. 137). On this analysis, Clinton acted from two motives: 1) to tell the truth as he saw it; and 2) to avoid an embarrassing sex scandal. The first motive is blameless on Kantian grounds (see below). The second motive appears indefensible because it involves a manipulation of the audience by the speaker and manipulation is impermissible in Kantian ethics. This argument is put succinctly by (Herman, 1993: p. 154 n28):

The moral question turns on whether I tell you what I believe to be true as information of use to you as well as me (and so contribute to the process of deliberation), or whether what I tell you is controlled by a commitment to regulate the flow of information in such a way that you can deliberate only as I will. Because our deliberative capacity is vulnerable to manipulation in this way, respect for rational agency requires a commitment to avoid intentional falsehoods and misleading truths.

In other words, the onus is on the speaker to avoid deliber- ately framing assertions in a way that the audience will misinterpret. In this crucial respect, misleading truths are no different than lies or, for that matter, even simple truths designed to manipulate the audience.

In Sandel's view, however, the onus is on the audience to interpret speakers with more care (p. 137):

If everyone who found himself in a dangerous or embarrassing situation resorted to carefully crafted [but true] evasions, people would not necessarily cease to believe them. Instead, people would learn to listen like lawyers and parse such statements with an eye to their literal meaning. This is exactly what happened when the press and the public became familiar with Clinton's carefully chosen words.

This defense may strike readers as formalistic, that is, an appeal to the "letter of the law" - the Categorical Imperative- and not its spirit. It also opens up the difficult problem of what sort of diligence the audience members owe themselves in interpreting what they hear.

In any event, both arguments depend upon establishing that telling a misleading truth is no different than either lying or truth-telling, respectively. Such arguments appear inconclusive because telling misleading truths bears resemblances to both. In the following sections, I review why this dilemma holds, and then suggest that telling a misleading truth is best compared not to simple truth-telling or lying but to telling leading truths. Through this comparison, the moral impermissibility of telling misleading truths becomes clearer, even on a formalistic understanding of Kantian ethics.

\section{Truth and Lies}

From a Kantian perspective, telling the truth is a simple affair. It consists of asserting something that you actually believe, with the intention that your listener should accept that you believe it, as evidenced by your assertion. The situation could be 


\section{SHELLEY}

captured as follows:

\section{Telling a truth}

Belief: you believe proposition A

A

Intent: you intend the listener should accept that you believe

Act: you assert A

Telling a lie is similarly straightforward. It consists of asserting something that you actually disbelieve, with the intention that your listener should accept that you believe it, as evidenced by your assertion. The situation could be captured as follows:

\section{Telling a lie}

Belief: you believe proposition $\sim \mathrm{A}$

Intent: you intend the listener should accept that you believe A

Act: you assert A

The difference between telling a truth and a lie resides in the different relationships between what the speaker believes and what the speakers intends for the audience to understand about that belief.

\section{Why Lying Is Morally Impermissible}

In Kantian ethics, lying, so construed, is immoral. This is so because it is self-defeating when universalized via the Categorical Imperative. To see this point, suppose that everyone made free to communicate with the sort of intent described for lying above. The intent is just the same as the intent for telling the truth, as is the act that you employ to communicate your intent. In that case, no listener could judge, merely from the act of asserting A, whether you actually believe A or you believe $\sim$ A. They could conclude only that you believe A or $\sim$ A. Since (A or $\sim A$ ) is not the same as $A$, your intention to have the listener accept that you believe $A$ is undermined. You cannot achieve your intent by lying. Thus, it is irrational to lie.

\section{Struth and Slies}

On this view, lying is impermissible because it can be confused with telling the truth. There is nothing inherently wrong with asserting A while believing $\sim \mathrm{A}$. The problem is that others will have no way of distinguishing this situation from the most obvious alternative, in which you assert A while believing A.

To make this point clearer, consider this scenario. A mad scientist creates a potion that causes people to assert the negation of what they intend to assert. In that case, two options for simple assertion are open, which I will call telling a "struth" and telling a "sly".

\section{Telling a struth}

Belief: you believe proposition A

Intent: you intend the listener should accept that you believe A

Act: you assert $\sim \mathrm{A}$

Note that this scheme is the same as telling a truth, except that the assertion is negated.

\section{Telling a sly}

Belief: you believe proposition $\sim \mathrm{A}$

Intent: you intend the listener should accept that you believe A

Act: you assert $\sim \mathrm{A}$

This scheme is the same as lying, except that the assertion is negated also.
This situation raises an interesting question: Is it morally permissible for you to tell a sly? There is nothing inherently faulty with this form of communication. However, if we take telling a struth as the default, then telling a sly is impermissible according to the Categorical Imperative. If everyone made free to tell slies, then no listener could be sure, when you assert $\sim \mathrm{A}$, whether you believe $\mathrm{A}$ or you believe $\sim \mathrm{A}$. In that case, they could conclude only that you believe A or $\sim \mathrm{A}$, which defeats the purpose of telling the sly.

The point of this scenario is to illustrate that the moral impermissibility of lying in the Kantian framework is not an inherent feature of lying. Instead, it derives from a comparison between telling a lie and telling a truth within a system of communication. To evaluate the permissibility of a linguistic action requires us to find an alternative with which it may most readily be confused. This point is crucial to evaluating the permissibility of telling misleading truths.

\section{Misleading Truths}

Telling a misleading truth consists of asserting something you believe with the intent that the audience will conclude that you believe some other claim that, in fact, you do not.

This situation may be captured as follows:

\section{Telling a misleading truth}

Belief: you believe propositions A and $\sim \mathrm{C}$

Intent: you intend the listener should accept that you believe A and $\mathrm{C}$

Act: you assert A

In this case, you rely on the assumption that the listener believes that you both hold that A implies C. Thus, when they accept that you believe A, they conclude-erroneously-that you believe $\mathrm{C}$ also.

In the case of President Clinton's testimony, the situation might be as follows:

$\mathrm{A}=\mathrm{I}$ did not have (mutual) sexual relations with that woman.

$\mathrm{C}=\mathrm{I}$ did not have any sexual relations with that woman.

President Clinton asserted A with the intention that his audience would conclude that he also believed C, although he did not. Thus, he told a misleading truth.

Sandel's argument that telling a misleading truth is morally permissible relies on assimilating it to simple truth-telling as described above. In both cases, the argument goes, proposition A is both believed and intended to be communicated. Since that feature is the crucial feature of truth-telling, which is known to be permissible, it follows that telling a misleading truth is also permissible. This is what Sandel means when he says that a misleading truth still "pays homage to the truth".

One problem with this argument is that it discounts the crucial difference between these situations, namely the difference in intentions. In the case of telling a simple truth, the intention stops with the goal of having the listener accept your belief in A. In the case of telling a misleading truth, the intention includes the goal of having the listener accept your belief in C. In this respect, telling a misleading truth is more akin to lying, in which the believed proposition and the intended communication are not equivalent. This objection is essentially that given by Herman. If so, then telling a misleading truth appears to be both permissible and impermissible from a Kantian viewpoint. Clearly, this state of affairs is not satisfactory. 


\section{Leading Truths}

It appears, then, that determining the permissibility of telling misleading truths cannot be settled through comparison with telling simple truths or lies. This situation suggests that perhaps neither comparison is appropriate. Indeed, there is another communicative action to be considered, namely telling a leading truth. In this act, you assert some proposition A with the intention of the listener accepting that you believe another proposition $\mathrm{C}$ that you do, in fact, believe. This situation may be captured as follows:

\section{Telling a leading truth}

Belief: you believe propositions A and C

Intent: you intend the listener should accept that you believe $\mathrm{A}$ and $\mathrm{C}$

Act: you assert A

In this case, you rely on the assumption that the listener believes that you both hold that $\mathrm{A}$ implies $\mathrm{C}$, as in the case of the misleading truth. Thus, when they accept your belief in A, they conclude - rightly - that you believe $\mathrm{C}$ also.

In an alternative version of the Clinton case, the propositions might be represented as follows:

$\mathrm{A}=$ I merely allowed that woman to pleasure me

$\mathrm{C}=\mathrm{I}$ did not have (mutual) sexual relations with that woman

Of course, this leading truth might not spare Clinton the brunt of the scandal he feared. Perhaps, though, the public might have been more forgiving of its greater candor.

It is clear from comparing the schemata for telling leading and misleading truths that they might be confused. Faced with the assertion $\mathrm{A}$, and believing that $\mathrm{A}$ implies $\mathrm{C}$, the listener could not be sure whether the speaker believes $\mathrm{C}$ or believes $\sim \mathrm{C}$. In that case, the listener could conclude only that the speaker believes $\mathrm{C}$ or $\sim \mathrm{C}$, which defeats the intention of telling a misleading truth. Thus, contrasted with telling a leading truth, telling a misleading truth is not permissible according to the Categorical Imperative.

\section{Conclusion}

Recent argument over the moral permissibility, from a Kantian perspective, of telling misleading truths has been framed in terms of comparisons with simple truth-telling or simple lying. This approach is inconclusive since misleading truths bear a significant resemblance to both.

On a formalist view of Kantian ethics, such as that described by Sandel, the resemblance of misleading truths and lies may be discounted. It is up to the audience to carefully parse the meaning of the assertions they encounter.

This article presents a formalist refutation of this defense. The refutation proceeds by shifting the comparison of misleading truths away from simple truths and lies over to telling leading truths. Telling a leading truth is the communicative action most readily confounded with telling a misleading truth. The possibility of confusion with leading truths means that telling a misleading truth is not consistent with the Categorical Imperative, and is thus morally impermissible on a formalist interprettation of Kantian ethics.

\section{REFERENCES}

Herman, B. (1993). The practice of moral judgment. Cambridge, MA: Harvard University Press.

Sandel, M. (2009). Justice: What's the right thing to do. New York, NY: Farrar, Straus and Giroux. 